\title{
Clinical patterns of postcholecystectomy syndrome
}

\author{
Bader Hamza Shirah ${ }^{1}$, Hamza Asaad Shirah², Syed Husham Zafar $^{3}$, and Khalid B Albeladi ${ }^{4}$
}

\begin{abstract}
${ }^{1}$ King Abdullah International Medical Research Center/King Saud bin Abdulaziz University for Health Sciences, Jeddah, Departments of ${ }^{2}$ General Surgery and ${ }^{3}$ Medicine, Al Ansar General Hospital, Medina,

${ }^{4}$ King Abdulaziz Medical City/King Saud bin Abdulaziz University for Health Sciences, Jeddah, Saudi Arabia
\end{abstract}

Backgrounds/Aims: Postcholecystectomy syndrome represents a heterogeneous group of symptoms and findings in patients who have previously undergone cholecystectomy. It is rare and under-reported in Saudi Arabia. It can be attributed to many complications such as bile duct injury, biliary leak, retained common bile duct stones, recurrent bile duct stones, and bile duct strictures. In this study, we aimed to analyze the causes and evaluate the approach to postcholecystectomy syndrome in our local Saudi Arabian community because of the vast number of cases encountered in our hospital for gallbladder clinical conditions and its related complications. Methods: A prospective cohort database analysis of 272 patients who were diagnosed and treated for postcholecystectomy syndrome between January 2000 and December 2013 were reviewed. Results: The incidence rate of postcholecystectomy syndrome was $19.8 \%$. The male to female ratio was $1: 1.45$. The mean age was $37.41 \pm 7.12$ years. The most common causes were as follows: No obvious cause in $50(18.4 \%)$ patients, Helicobacter pylori infection in $43(15.8 \%)$, pancreatitis in 42 (15.4\%), peptic ulcer disease in $41(15.1 \%)$, recurrent common bile duct (CBD) stone in $26(9.6 \%)$, retained CBD stone in $22(8.1 \%)$, bile leakage in $19(7 \%)$, stenosis of the sphincter of Oddi in $12(4.4 \%)$, cystic duct stump syndrome in $11(4 \%)$, and CBD Stricture in $5(1.8 \%)$. The mortality rate was $0 \%$. Conclusions: Any clinical presentation of postcholecystectomy should not be underestimated and be thoroughly investigated. Multidisciplinary collaboration is crucial for the best outcome and a safe approach for all the patients. (Ann Hepatobiliary Pancreat Surg 2018;22:52-57)

Key Words: Postcholecystectomy syndrome; Laparoscopic cholecystectomy; Gallstones; Bile duct injury; Biliary leak; Jaundice

\section{INTRODUCTION}

Postcholecystectomy syndrome is known as the recurrence of a complex group of heterogeneous symptoms similar to those experienced before a cholecystectomy. They commonly manifest as upper abdominal pain (primarily the right upper quadrant) and dyspepsia, with or without jaundice, and can be early, if occurring in the postoperative period, and late, if it manifests after months or years. ${ }^{1,2}$

Postcholecystectomy syndrome was described by Womack and Crider for the first time in 1947 as "the presence of symptoms after cholecystectomy". The incidence varies widely in the literature; it has been reported in many clinical studies to be between $5-15 \%, 5-30 \%$, and
$15-47 \%$ with $10-15 \%$ being the most reasonable range. The onset of symptoms may vary from 2 days to 25 years. ${ }^{3}$ The incidence of recurrent symptoms in female patients was reported as $43 \%$, compared to $28 \%$ among male patients. $^{3,4}$

Severe symptoms are more likely to represent a complication of cholecystectomy if they occur early or to express treatable causes when compared to non-specific, or mild symptoms. However, if no calculi or gallbladder abnormalities were detected during the cholecystectomy while the presenting symptoms are similar to the preoperative ones, a non-biliary etiology should be considered. ${ }^{3}$

The most common cause of the postcholecystectomy syndrome is an overlooked extrabiliary disorder such as reflux esophagitis, peptic ulceration, irritable bowel syn-

Received: August 7, 2017; Revised: August 31, 2017; Accepted: September 17, 2017

Corresponding author: Bader Hamza Shirah

King Abdullah International Medical Research Center/King Saud bin Abdulaziz University for Health Sciences, P.O.Box: 65362, Jeddah, 21556, Saudi Arabia

Tel: +966506201963, E-mail: shirah007@ksau-hs.edu.sa

Copyright (C) 2018 by The Korean Association of Hepato-Biliary-Pancreatic Surgery

This is an Open Access article distributed under the terms of the Creative Commons Attribution Non-Commercial License (http://creativecommons.org/ licenses/by-nc/4.0) which permits unrestricted non-commercial use, distribution, and reproduction in any medium, provided the original work is properly cited. Annals of Hepato-Biliary-Pancreatic Surgery - pISSN: 2508-5778 - elSSN: 2508-5859 
drome or chronic pancreatitis. ${ }^{1-5}$ The biliary etiologies include bile salt-induced diarrhea or gastritis, abscess, chronic biloma, retained calculi, dropped calculi, bile leak, biliary strictures, long cystic duct remnant, stenosis, and dyskinesia of the sphincter of Oddi. ${ }^{4}$ The primary reported extrabiliary causes include gastrointestinal causes like acute/chronic pancreatitis (and complications), pancreatic tumors, pancreas divisum, hepatitis, esophageal diseases, peptic ulcer disease, mesenteric ischemia, diverticulitis, and organic or motor intestinal disorders. It also includes extra-intestinal causes like psychiatric and neurological disorders, coronary artery disease, intercostal neuritis, wound neuroma, and unexplained pain syndromes. ${ }^{5}$

The imaging approach to postcholecystectomy syndrome includes ultrasonography, computed tomography (CT) scan, endoscopic retrograde cholangiopancreatography (ERCP), and magnetic resonance cholangiopancreatography (MRCP). ${ }^{6-9}$

The management of the options for postcholecystectomy syndrome are focused on the treatment of the particular cause. Many articles reported different approaches to each etiology, which causes the syndrome to experience various success and morbidity rates. The recent advances in the laparoscopic and endoscopic therapeutic options have led to a decrease in open exploration surgical methods. ${ }^{10}$

Postcholecystectomy syndrome is under-reported in Saudi Arabia, as evidenced by a thorough literature search, despite the high prevalence of gallbladder stones, diseases, and complications. Therefore, we aimed in this study to analyze the causes and evaluate the approach to the postcholecystectomy syndrome in our local Saudi Arabian community because of the vast number of cases encountered in our hospital for gallbladder clinical conditions and its related complications.

\section{MATERIALS AND METHODS}

A prospective cohort database analysis of the results of 1374 patients who were diagnosed and surgically treated (open or laparoscopic) for gallstone diseases were reviewed. Of those, 272 patients were readmitted to the surgical ward or managed in the outpatient department for postcholecystectomy syndrome between January 2000 and December 2013 in Al Ansar general public health hospital in Medina, Saudi Arabia. Ethical approval was granted from Al Ansar hospital's ethical committee and the management guidelines and clinical pathway subcommittee of the quality care program at the same hospital.

All of the patients who presented in the acute form were admitted to the emergency department, and those presenting with chronic diseases were admitted to the outpatient surgical clinics. Patients in whom the diagnosis of medically treatable causes was proven continued their treatment as outpatient clinic cases or were referred to the proper medical specialty for specific treatment. The inclusion criteria included adult patients (older than 12 years old as per the Saudi Arabian Ministry of Health age guidelines), who had previously proved diagnosis and treatment of a gallstone disease and presented with symptoms and signs of postcholecystectomy syndrome. There were no exclusion criteria.

All of the patients had the same work up (complete blood count, coagulation profile, blood chemistry, chest $\mathrm{x}$-ray, electrocardiogram, abdominal ultrasound, and computed tomography scan), and in particular cases, an ERCP and upper gastrointestinal endoscopy were conducted. The medical management or surgical procedure care were carefully discussed with the patients. Regarding the related surgical cases, the elective included cases were admitted to the surgical floor one day before any surgical or other intervention procedure. The emergency cases were admitted directly from the emergency department. As part of the clinical pathway of our quality care program, a computerized database file was used to document all of the patients' data.

The Statistical Package for Social Sciences (SPSS) software, version 22, was used for data analyses. The results were represented by absolute percentages and means.

\section{RESULTS}

Out of 1,374 patients with gallstone diseases who had a cholecystectomy, 272 patients were diagnosed with postcholecystectomy syndrome. The incidence rate of postcholecystectomy syndrome was $19.8 \%$. The male to female ratio was $1: 1.45,111(40.8 \%)$ were male patients while $161(59.2 \%)$ were females. The mean age of the patients was $37.41 \pm 7.12$ years with an age range of 28 to 55 years.

The presenting symptoms were recorded as right upper 
quadrant abdominal pain in $197(72.4 \%)$ patients, nausea in $138(50.7 \%)$, vomiting in $91(33.5 \%)$, dyspepsia in 83 (30.5\%), abdominal colic in $64(23.5 \%)$, and fever in 37 $(13.6 \%)$. The presenting signs were recorded as right upper quadrant abdominal tenderness in 125 (45.9\%), jaundice in $48(17.6 \%)$, generalized abdominal tenderness in 39 (14.3\%), and epigastric tenderness in 22 (8\%) (Table 1).

Of the $272(100 \%)$ patients diagnosed with the postcholecystectomy syndrome, 134 (49.3\%) were admitted electively, while 138 (50.7\%) were admitted from the emergency department. The diagnostic laboratory data displayed high liver enzymes in 73 (26.8\%) patients, high bilirubin in 47 (17.3\%), positive Helicobacter pylori serology in $43(15.8 \%)$, high alkaline phosphatase in 34 $(12.5 \%)$, high amylase in $31(11.4 \%)$, and high WBC in $27(9.9 \%)$.

The ultrasounds detected a retained common bile duct (CBD) stone in $22(8 \%)$ patients, recurrent CBD stone in 26 (9.6\%), dilated CBD in 24 (8.8\%), bile leakage in 19 (6.98\%), free intraperitoneal fluid collection in $18(6.6 \%)$, and cystic duct stump remnant in $11(4 \%)$. The CT scan exhibited features of pancreatitis in 42 (15.4\%) patients, dilated intrahepatic tree in $26(9.6 \%)$, dilated CBD in 24 $(8.8 \%)$, free intraperitoneal fluid collection in $23(8.5 \%)$, and narrowing of the supra pancreatic common duct in 9 (3.3\%). The ERCP diagnosed stenosis of the sphincter of Oddi in $12(4.4 \%)$ patients, cystic duct stump syndrome in $11(4 \%)$, and CBD stricture in $5(1.8 \%)$. Upper gastrointestinal endoscopy diagnosed peptic ulcer disease in 41 (15.1\%) patients (Table 2).

The most common causes of postcholecystectomy syn-

Table 1. The presenting symptoms and signs of postcholecystectomy syndrome in a local Saudi Arabian community

\begin{tabular}{lcc}
\hline \multicolumn{1}{c}{ Presenting symptoms $P$} & $\begin{array}{c}\text { Number of } \\
\text { patients }\end{array}$ & \\
\hline Right upper quadrant abdominal pain & 197 & $72.4 \%$ \\
Nausea & 138 & $50.7 \%$ \\
Vomiting & 91 & $33.5 \%$ \\
Dyspepsia & 83 & $30.5 \%$ \\
Abdominal colic & 64 & $23.5 \%$ \\
Fever & 37 & $13.6 \%$ \\
The presenting signs & & \\
$\quad$ Right upper quadrant abdominal & 125 & $45.9 \%$ \\
$\quad$ tenderness & & \\
$\quad$ Jaundice & 48 & $17.6 \%$ \\
$\quad$ Generalized abdominal tenderness & 39 & $14.3 \%$ \\
$\quad$ Epigastric tenderness & 22 & $8 \%$ \\
\hline
\end{tabular}

drome recorded were as follows: No obvious cause in 50 (18.4\%) patients (18 males and 32 females), helicobacter pylori infection in $43(15.8 \%)$ patients (20 males and 23 females), pancreatitis in 42 (15.4\%) patients (19 males and 23 females), peptic ulcer disease in 41 (15.1\%) patients (24 males and 17 females), recurrent CBD stone in $26(9.6 \%)$ patients (7 males and 19 females), retained CBD stone in $22(8.1 \%)$ patients (9 males and 13 females), bile leakage in 19 (7\%) patients (6 males and 13 females), stenosis of the sphincter of Oddi in 12 (4.4\%) patients (4 males and 8 females), cystic duct stump syndrome in 11 (4\%) patients ( 3 males and 8 females), and CBD stricture in $5(1.8 \%)$ patients (1 male and 4 females) (Fig. 1).

The offered treatment modalities were different depending on the particular cause. For the no obvious cause patients, management included reassurance, supportive treatment (analgesia), and discharge. All of the Helicobacter

Table 2. The diagnostic data of postcholecystectomy syndrome in a local Saudi Arabian community

\begin{tabular}{lcc}
\hline \multicolumn{1}{c}{ The diagnostic data } & $\begin{array}{c}\text { Number } \\
\text { of patients }\end{array}$ & Percentage \\
\hline Laboratory & & \\
High liver enzymes & 73 & $26.8 \%$ \\
High bilirubin & 47 & $17.3 \%$ \\
Positive Helicobacter Pylori serology & 43 & $15.8 \%$ \\
High alkaline phosphatase & 34 & $12.5 \%$ \\
High amylase & 31 & $11.4 \%$ \\
High WBC & 27 & $9.9 \%$ \\
Ultrasound & & \\
Retained CBD stone & 22 & $8 \%$ \\
Recurrent CBD stone & 26 & $9.6 \%$ \\
Dilated CBD & 24 & $8.8 \%$ \\
Bile leakage & 19 & $7 \%$ \\
Free intraperitoneal fluid collection & 18 & $6.6 \%$ \\
Cystic duct stump remnant & 11 & $4 \%$ \\
Computed tomography & & \\
Features of pancreatitis & 42 & $15.4 \%$ \\
Dilated intrahepatic tree & 26 & $9.6 \%$ \\
Dilated CBD & 24 & $8.8 \%$ \\
Free intraperitoneal fluid collection & 23 & $8.5 \%$ \\
Narrowing of the supra pancreatic & 9 & $3.3 \%$ \\
$\quad$ common duct & & \\
Endoscopic retrograde cholangiopancreatography & \\
Stenosis of the sphincter of Oddi & 12 & $4.4 \%$ \\
Cystic duct stump syndrome & 11 & $4 \%$ \\
CBD stricture & 5 & $1.8 \%$ \\
Upper gastrointestinal endoscopy & & \\
Peptic ulcer disease & 41 & $15.1 \%$ \\
\hline & & \\
\hline
\end{tabular}




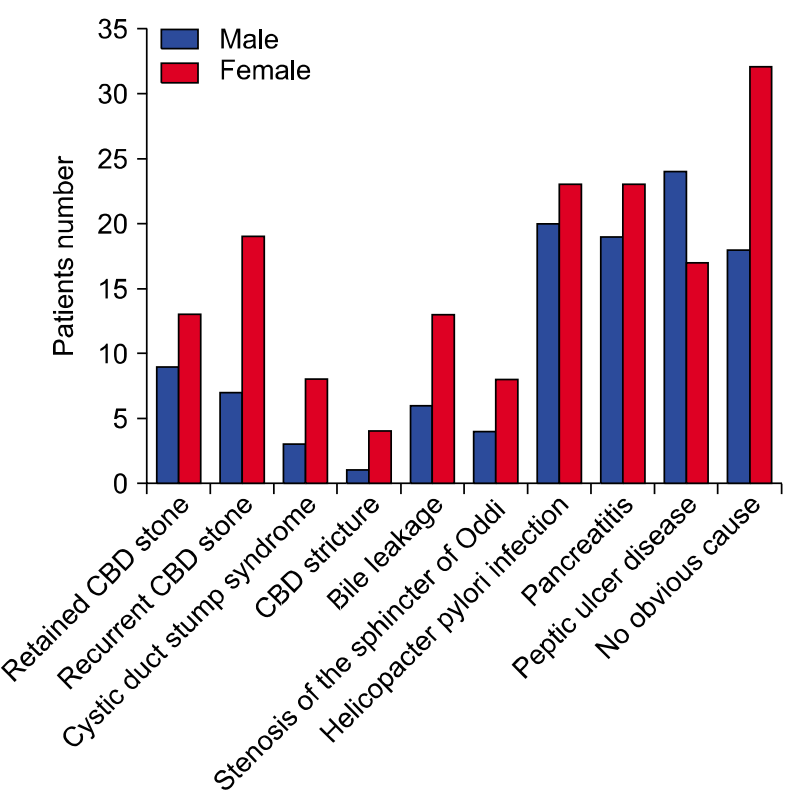

The causes of the postcholecystectomy syndrome

Fig. 1. The causes of postcholecystectomy syndrome in the local Saudi Arabian community. CBD, common bile duct.

pylori infection cases were referred to gastroenterology for treatment and follow up in the outpatient surgical clinics for three months. Regarding pancreatitis, 11 patients were admitted to the intensive care unit and medically treated; while 31 patients were admitted to the surgical floor and medically treated. No surgical intervention was needed. After being discharged, all of the patients had follow up appointments at the outpatient surgical clinics for three months. As for peptic ulcer disease, they were treated medically in collaboration with gastroenterology and followed up at the outpatient surgical clinics for three months.

Concerning recurrent $\mathrm{CBD}$ stone, the patients were treated by ERCP, endoscopy, papillotomy, stone extraction, and stenting. No surgical intervention was needed, and patients had follow up appointments at the outpatient surgical clinics for three weeks. For retained CBD stones, the patients were treated by ERCP, endoscopy, papillotomy, stone extraction, and stenting. No surgical intervention was needed, and the patients had follow up appointments at the outpatient surgical clinics for three weeks. For bile leakage, 12 patients had a laparotomy and repair; while 7 patients had a laparoscopic repair. The patients were followed up by the outpatient surgical clinics for three months. For stenosis of the sphincter of Oddi,

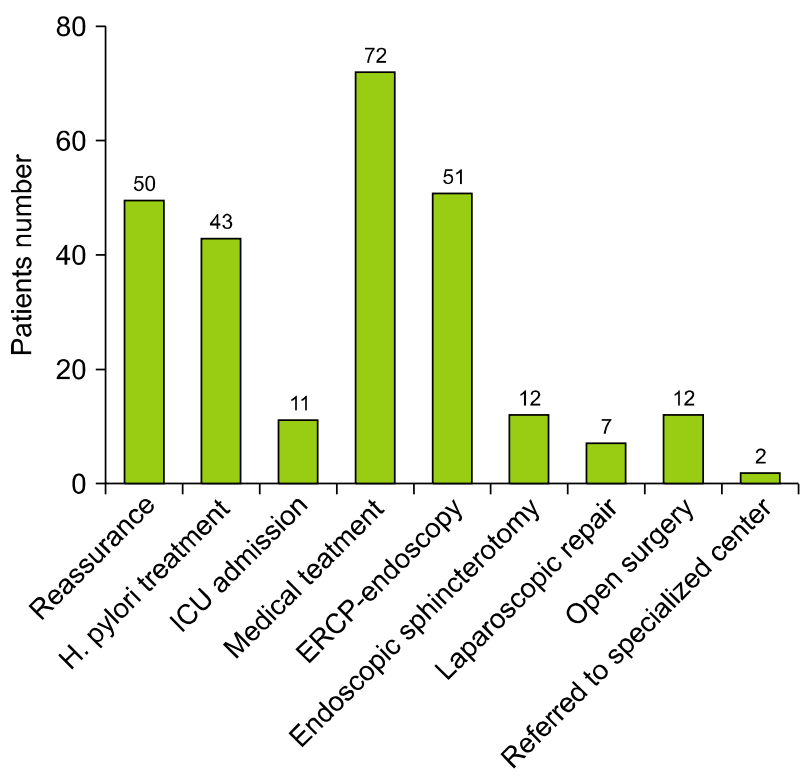

Fig. 2. The treatment modalities offered to the specific causes of postcholecystectomy syndrome in the local Saudi Arabian community. ICU, intensive care unit; ERCP, endoscopic retrograde cholangiopancreatography.

all patients had endoscopic sphincterotomy and stenting, and they were followed up by the outpatient surgical clinics for two months.

For cystic duct stump syndrome, all patients had laparoscopic repair and were followed up by the outpatient surgical clinics for two months. For CBD structure, 3 patients had mild stenosis and were treated by ERCP, endoscopy, and stenting; while 2 patients had severe stenosis and were referred to a specialized tertiary care center. All of the patients were followed up by the outpatient surgical clinics for three months. The mortality rate was $0 \%$ (Fig. 2).

\section{DISCUSSION}

The incidence rate of the postcholecystectomy syndrome in this study's population was $19.8 \%$, which is aligned with the average reported rates worldwide despite the younger mean age of the patients, $37.41 \pm 7.12$ years. This outcome could be attributed to the fact that most of the patients presenting with gallstones and diseases in our local community belonged to the same young age groups compared to the reported age groups worldwide.

The presenting symptoms and signs in this study were similar to those reported internationally. We observed that most of the patients presented with only one or two find- 
ings; however, no one presented with all or multiple complaints. In general, some symptoms and signs were specific and directive to the cause, like dyspepsia and epigastric pain for peptic ulcer and Helicobacter pylori infection, but most of the others were vague and general which necessitated a full workup to identify the cause. Any clinical presentation of postcholecystectomy should not be underestimated and be thoroughly investigated; it is a lesson that we adopted as a protocol in our clinical pathway.

In most of our cases, the management approach was a multidisciplinary one involving surgical, medical, radiological, critical care, and other specialties. It was a significant pathway to the success of the treatment and the result of zero mortality. We recommend the collaboration of as many specialties as needed, as early as possible, for the best outcome and the safest approach for all patients.

In this study, CBD stones or cystic duct remnants were found in $48(17.6 \%)$ patients, remnant or recurrent. They are reported internationally as the most common cause of postcholecystectomy syndrome. Stones are traditionally classified as retained or recurrent if found before or after two years following surgery. Occluding stones left in the stump of the cystic duct may account for $17-25 \%$ of the cases of postcholecystectomy syndrome. ${ }^{11}$

The reported rate of bile duct injuries is slightly higher using laparoscopic surgery than open surgery $(0.5 \%$ and $0.15 \%$, respectively). The leading causes of bile ductal injury include the erroneous cutting of bile ducts, inadvertently placed clips or ligatures, and periductal bile leakage resulting in fibrosis and thermal injury owing to electrocautery. A bile duct injury usually manifests as a leak, stricture or transection. The most common sites of biliary leaks include injured bile ducts, the cystic duct stump, and the gallbladder stump. Intraperitoneal fluid collections in the gallbladder bed occur in up to $14 \%$ of the patients who had a cholecystectomy, and most will resolve spontaneously; however, collections persisting for more than a week or fluid outside the gallbladder bed should raise the suspicion of a biliary leak or injury. ${ }^{12,13}$ In our series, a bile leakage was found in 19 (7\%) patients, in which 12 had a loose surgical clip at the cystic duct remnant that was treated laparoscopically by clipping. Seven patients had a mild CBD injury, generally a small tear, that needed only suturing repair.
Many published international reports proposed that the length of a cystic duct remnant that is greater than $1 \mathrm{~cm}$ in length after cholecystectomy may be the cause of postcholecystectomy syndrome and refer to it as cystic duct stump syndrome. In fact, several articles have reported that a cystic duct remnant caused symptoms even after the duct calculi had been removed. ${ }^{14}$ In our study, cystic duct stump syndrome was found in $11(4 \%)$ patients and 4 of them had a small retained stone which was removed endoscopically. The remaining patients needed a shortening of the stump laparoscopically.

CBD strictures occur in up to $0.6 \%$ of the cases after cholecystectomy. If it was not involved with previously injured anatomical variants, strictures usually occurred because the CBD was injured during the clamping or ligation of the cystic duct close to its insertion. Strictures are the most common late complication of biliary surgery, developing a few months to years after cholecystectomy. ${ }^{15}$ It was proven in $5(1.8 \%)$ patients in our series in which 3 patients had mild stenosis that was treated by ERCPendoscopy-stenting, 2 patients had severe stenosis and were referred to a specialized tertiary care center.

Dysfunction of the sphincter of Oddi was implicated in the etiology of postcholecystectomy syndrome as a result from a real stenosis or secondary to spasm of the sphincter, which occurred many years following the cholecystectomy and could be diagnosed in $9-11 \%$ of patients with abdominal pain. In the majority of patients, the dysfunction continues to present problems both regarding the diagnosis as well as the treatment. Although muscle spasm is supposed to play a significant role in such cases, the response to smooth muscle relaxants like nitrates and calcium channel antagonists has been disappointing. ${ }^{16,17}$ In $12(4.4 \%)$ patients of this study's population, the diagnosis was achieved by ERCP and manometry; all were treated by stenting endoscopically with a good outcome.

Cholecystectomy itself is associated with many physiological changes in the upper gastrointestinal tract that may account for the persistence of the symptoms or the development of new symptoms after gallbladder removal. The cholecystosphincter of the Oddi reflex, cholecysto-antral reflex, and cholecyst-esophageal reflexes are all disrupted, and some local upper gastrointestinal hormonal changes often occur after cholecystectomy. Therefore, there is an increased incidence of gastritis, alkaline duodenogastric reflux, and 
gastro-esophageal reflux after cholecystectomy, which may be the basis for postcholecystectomy symptoms. ${ }^{18-20}$ In our study, no obvious cause was documented in 50 (18.4\%) patients despite an extensive full work up.

Helicobacter pylori, a gram-negative bacillus, has been recognized as a public health problem in approximately half of the world population. The reported prevalence of Helicobacter pylori in Riyadh, Saudi Arabia by Marie ${ }^{21}$ was $67 \%$, and in South-Western Saudi Arabia by Ayoola et al. ${ }^{22}$ was $50-80 \%$, and in Makkah, Saudi Arabia by Khan and $\mathrm{Ghazi}^{23}$ was $61 \%$. It has been implicated as a risk factor for variant extraintestinal clinical manifestations including many hepatobiliary diseases such as calcular cholecystitis, primary biliary sclerosing cholangitis, gallbladder cancer and primary hepatic carcinomas. In this study, Helicobacter pylori infection was proven in 43 (15.8\%) patients, 20 males, and 23 females. During our 20 years of clinical practice, we noticed a sharp rising pattern in Helicobacter pylori infection in most of our surgical patients, both symptomatic or incidental finding, a topic that we are currently investigating in a clinical study.

In conclusion, any clinical presentation of postcholecystectomy should not be underestimated and be thoroughly investigated. Multidisciplinary collaboration is crucial for the best outcome and the safest approach for all of the patients. We recommend conducting scientific, clinical studies to investigate postcholecystectomy syndrome in Saudi Arabia. We also encourage all medical centers dealing with quite good numbers of patients of gallstones and diseases to report their result for the accumulation of sufficient clinical data and exploring the different management approaches and strategies.

\section{REFERENCES}

1. Schofer JM. Biliary causes of postcholecystectomy syndrome. J Emerg Med 2010;39:406-410.

2. Jaunoo SS, Mohandas S, Almond LM. Postcholecystectomy syndrome (PCS). Int J Surg 2010;8:15-17.

3. Redwan AA. Multidisciplinary approaches for management of postcholecystectomy problems (surgery, endoscopy, and percutaneous approaches). Surg Laparosc Endosc Percutan Tech 2009; 19:459-469.

4. Madacsy L, Dubravcsik Z, Szepes A. Postcholecystectomy syndrome: from pathophysiology to differential diagnosis - a critical review. Pancreat Disord Ther 2015;5:162.

5. Girometti R, Brondani G, Cereser L, Como G, Del Pin M,
Bazzocchi M, et al. Post-cholecystectomy syndrome: spectrum of biliary findings at magnetic resonance cholangiopancreatography. Br J Radiol 2010;83:351-361.

6. Terhaar OA, Abbas S, Thornton FJ, Duke D, O'Kelly P, Abdullah $\mathrm{K}$, et al. Imaging patients with "post-cholecystectomy syndrome": an algorithmic approach. Clin Radiol 2005;60:78-84.

7. Wani NA, Khan NA, Shah AI, Khan AQ. Post-cholecystectomy Mirizzi's syndrome: magnetic resonance cholangiopancreatography demonstration. Saudi J Gastroenterol 2010;16:295-298.

8. Coté GA, Ansstas M, Shah S, Keswani RN, Alkade S, Jonnalagadda $\mathrm{SS}$, et al. Findings at endoscopic retrograde cholangiopancreatography after endoscopic treatment of postcholecystectomy bile leaks. Surg Endosc 2010;24:1752-1756.

9. Pinkas H, Brady PG. Biliary leaks after laparoscopic cholecystectomy: time to stent or time to drain. Hepatobiliary Pancreat Dis Int 2008;7:628-632.

10. Topazian M, Hong-Curtis J, Li J, Wells C. Improved predictors of outcome in postcholecystectomy pain. J Clin Gastroenterol 2004;38:692-696.

11. Walsh RM, Ponsky JL, Dumot J. Retained gallbladder/cystic duct remnant calculi as a cause of postcholecystectomy pain. Surg Endosc 2002;16:981-984.

12. Sakai Y, Tsuyuguchi T, Ishihara T, Sugiyama H, Miyakawa K, Yukisawa S, et al. The usefulness of endoscopic transpapillary procedure in post-cholecystectomy bile duct stricture and post-cholecystectomy bile leakage. Hepatogastroenterology 2009; 56:978-983.

13. Berger H, Weinzierl M, Neville ES, Pratschke E. Percutaneous transcatheter occlusion of cystic duct stump in postcholecystectomy bile leakage. Gastrointest Radiol 1989;14:334-336.

14. Shaw C, O'Hanlon DM, Fenlon HM, McEntee GP. Cystic duct remnant and the 'post-cholecystectomy syndrome'. Hepatogastroenterology 2004;51:36-38.

15. Lum YW, House MG, Hayanga AJ, Schweitzer M. Postcholecystectomy syndrome in the laparoscopic era. J Laparoendosc Adv Surg Tech A 2006;16:482-485.

16. Zhou PH, Liu FL, Yao LQ, Qin XY. Endoscopic diagnosis and treatment of post-cholecystectomy syndrome. Hepatobiliary Pancreat Dis Int 2003;2:117-120.

17. Kalaitzakis E, Ambrose T, Phillips-Hughes J, Collier J, Chapman RW. Management of patients with biliary sphincter of Oddi disorder without sphincter of Oddi manometry. BMC Gastroenterol 2010;10:124.

18. Phillips MR, Joseph M, Dellon ES, Grimm I, Farrell TM, Rupp CC. Surgical and endoscopic management of remnant cystic duct lithiasis after cholecystectomy--a case series. J Gastrointest Surg 2014;18:1278-1283.

19. Filip M, Saftoiu A, Popescu C, Gheonea DI, Iordache S, Sandulescu L, et al. Postcholecystectomy syndrome - an algorithmic approach. J Gastrointestin Liver Dis 2009;18:67-71.

20. Rogy MA, Függer R, Herbst F, Schulz F. Reoperation after cholecystectomy. The role of the cystic duct stump. HPB Surg 1991;4:129-134.

21. Marie MA. Seroprevalence of Helicobacter pylori infection in large series of patients in an urban area of Saudi Arabia. Korean J Gastroenterol 2008;52:226-229.

22. Ayoola AE, Ageely HM, Gadour MO, Pathak VP. Prevalence of Helicobacter pylori infection among patients with dyspepsia in South-Western Saudi Arabia. Saudi Med J 2004;25:1433-1438.

23. Khan MA, Ghazi HO. Helicobacter pylori infection in asymptomatic subjects in Makkah, Saudi Arabia. J Pak Med Assoc 2007;57:114-117. 